\title{
Investigação antibacteriana in vitro de extratos etanólicos das folhas e cascas de Cedrela fissilis Vell.
}

\author{
In vitro antibacterial of research ethanol extract from leaves and \\ bark of Cedrela fissilis Vell.
}

Bruna Carminate ${ }^{1}$, Camilo Amaro de Carvalho*2, Thiago Ferreira Pacheco ${ }^{1}$, Vinícius Dornellas Natalli ${ }^{1}$ e Marcelo Barreto da Silva ${ }^{1}$

\author{
${ }^{1}$ Departamento de Ciências Agrárias e Biológicas, Universidade Federal do Espírito Santo (UFES-CEUNES), \\ São Mateus, Brasil \\ ${ }^{2}$ Departamento de Medicina e Enfermagem, Universidade Federal de Viçosa (UFV), Viçosa, Brasil
}

\begin{abstract}
Resumo
O Brasil apresenta grande potencial para a obtenção de novos fármacos de origem natural capazes de combater infecções causadas por microrganismos resistentes aos antibióticos convencionais. O presente estudo visou realizar uma análise fitoquímica e investigar a atividade antibacteriana in vitro dos extratos etanólicos das cascas e folhas de Cedrela fissillis. Estes foram obtidos por turboextração, concentrados e liofilizados. Na análise fitoquímica do extrato da casca encontro-se: saponinas, fenóis, taninos pirogálicos e triterpenóides. No extrato das folhas detectou-se a presença de taninos catéquicos. Para determinação da concentração inibitória mínima (CIM), foi utilizada a técnica de diluição em microplaca. Após a leitura da CIM, nos poços onde não foi observado crescimento bacteriano foi determinada a concentração bactericida mínima (CBM). Os extratos das cascas indicou atividade antibacteriana frente a Escherichia coli (ATCC 8739), Staphylococcus aureus (ATCC 25923), Bacillus cereus (ATCC 11778) e Staphylococcus aureus hospitalar, com CIM de $125 \mu \mathrm{g} . \mathrm{mL}^{-1}$. Através da CBM constatou-se uma significativa atividade bactericida diante das quatro espécies bacterianas. O extrato das folhas não apresentou atividade antibacteriana frente as cepas testadas. O estudo mostrou a existência de constituintes com potencial antibacteriano presente no extrato etanólico das cascas de Cedrela fissilis Vell. contra as quatro cepas avaliadas.
\end{abstract}

Palavras-chave: Antimicrobianos, Cedrela fissilis, plantas medicinais, extratos vegetais.

\begin{abstract}
Brazil has great potential for obtaining new drugs of natural origin able to fight infections caused by resistant microorganisms to conventional antibiotics. This study aimed to perform a phy tochemical analysis and to investigate the in vitro antibacterial activity of ethanol extracts of the bark and leaves of Cedrela fissillis. These were obtained by turboextraction, concentrated and lyophilized. In phytochemical analysis of the extract of the bark against yourself, saponins, phenols, tannins and triterpenoids pirogálicos. In leaf extract detected the presence of catechin tannins. For determination of minimum inhibitory concentration (MIC), the microplate dilution technique was used. After reading the MIC in wells where no bacterial growth was observed in minimal bactericidal concentration $(M B C)$ was determined. Extracts of the hulls indicated antibacterial activity against Escherichia coli (ATCC 8739), Staphylococcus aureus (ATCC 25923), Bacillus cereus (ATCC 11778) and Staphylococcus aureus hospital with CIM $125 \mu \mathrm{g} \cdot \mathrm{mL}^{-1}$. By CBM found a significant bactericidal activity against the four bacterial species. The leaf extract showed no antibacterial activity against the tested strains. The study showed the existence of constituents with antimicrobial activity present in the ethanol extract of the bark of Cedrela Cedrela Vell. against these strains evaluated.
\end{abstract}

Keywords: Antibacterial, Cedrela fissilis, medicinal plants, plant Extracts.

\footnotetext{
* camilo.carvalho@ufv.br
}

Recebido: 20/03/2014 Aceito: 20/03/2014 


\section{Introdução}

$\mathrm{O}$ Brasil é o país que detém a maior parcela da biodiversidade, em torno de 15 a 20\% do total mundial, com destaque para as plantas superiores, nas quais detém aproximadamente $24 \%$ da biodiversidade. Entre os elementos que compõem a biodiversidade, as plantas são a matéria-prima para a fabricação de fitoterápicos e outros medicamentos (Brasil, 2006). A diversidade de espécies de plantas presentes no Brasil continua representando um caminho para a descoberta de novos fármacos destinados ao tratamento de patologias que ainda hoje necessitam de inovações (Salvagnini et al., 2008; Bonella et al., 2011). Associado ao seu uso como substrato para a fabricação de medicamentos, as plantas são também utilizadas em práticas populares e tradicionais como remédios caseiros e comunitários, processo conhecido como medicina tradicional. Além desse acervo genético, o Brasil é detentor de rica diversidade cultural e étnica que resultou em um acúmulo considerável de conhecimentos e tecnologias tradicionais, passados de geração a geração, entre os quais se destaca o vasto acervo de conhecimentos sobre manejo e uso de plantas medicinais (Brasil, 2006).

A resistência de bactérias aos antibióticos disponíveis clinicamente se tornou um problema de saúde pública em todo mundo. Além disso, o custo financeiro de uma terapia fracassada por conta de microrganismos resistentes é muito grande, onerando ainda mais os sistemas públicos de saúde (DEL FIOL et al., 2010). Estes constituem os únicos medicamentos que influenciam não apenas no paciente em tratamento, mas em todo o ecossistema onde está inserido, com repercussões potencialmente profundas (AVORN e SOLOMON, 2000). Esta preocupação mundial faz com que a resistência bacteriana seja objeto de diversas publicações sobre antimicrobianos (WANNMACHER, 2004).

De acordo com Freitas et al. (2002), o uso excessivo e inadequado de antibióticos tem contribuído para o aumento da resistência microbiana. Embora o desenvolvimento da resistência seja um fenômeno espontâneo, as drogas atuam como agentes seletores de amostras resistentes. Com o passar do tempo vão surgindo microrganismos resistentes a vários fármacos (Chaves et al., 2011).

Estudos mostram que o desenvolvimento da resistência de microrganismos aos antibióticos correntemente em uso tem sido rápido e progressivo, que associado à baixa taxa de descoberta de novas substâncias com potencial antimicrobiano, é a causa de preocupação pela comunidade científica. Além do linezolide (Zyvox®), a última classe de antibióticos que chegou ao mercado farmacêutico dos EUA foi há 30 anos (White, 2003). Sendo assim, uma das medidas utilizadas na batalha contra a resistência bacteriana é a modificação dos antibióticos em uso; no entanto, pouco sucesso tem sido obtido. Por esses motivos, a descoberta de novas moléculas, de fonte natural ou sintética, com atividade antimicrobiana é assunto de máxima urgência. A variedade de moléculas presentes em plantas faz das mesmas promissoras fontes inovadoras de agentes antimicrobianos (Leitão et al., 2006; Silva et al., 2007, 2008; Coutinho et al., 2008).

A Cedrela fissilis Vell. é uma arbórea conhecida popularmente como cedro batata, cedro rosa ou cedro branco, nativa do Brasil e de ocorrência do Rio Grande do Sul até Minas Gerais, encontrada nas florestas semidecídua e pluvial atlântica (Lorenzi, 1992). Sua floração ocorre de setembro a dezembro e os frutos amadurecem após a queda das folhas, entre julho e agosto, sendo que uma árvore isolada chega a produzir mais de 1.500 frutos, com mais de 60.000 sementes férteis (Reitz et al., 1983; Carvalho, 1994; Rizzini, 1981; Corvello et al., 1999). A madeira $C$. fissilis tem sido muito utilizada pela indústria na fabricação de móveis, e na medicina popular o chá das folhas e das cascas é empregado como adstringente, emético, febrífuga, anti-reumática, antimalárica, no combate à leucorréia e na lavagem de feridas e úlceras (Corrêa, 1931; Lorenzi e Matos, 2008). Neste contesto, o objetivo deste trabalho foi avaliar as classes fitoquímicas e a atividade antibacteriana de extratos etanólicos de Cedrela fissilis Vell.

\section{Material e métodos}

\subsection{Obtenção do material vegetal e preparação do extrato vegetal}

Amostras de cascas do caule e folhas de Cedrela fissilis Vell., foram coletadas no Horto de Plantas Medicinais do Centro Comunitário Franco Rossetti, localizado no município de Pedro Canário, ES. Em seguida procedeu-se com a identificação da espécie por meio de identificadas conforme descrição de Lorenzi \& Matos (2002), sendo as exsicatas depositadas em Herbário. As cascas (105 g) e folhas $(81 \mathrm{~g})$ foram desidratadas em estufa $\left(40 \pm 5^{\circ} \mathrm{C}\right)$ com ventilação forçada por 72 horas, e posteriormente moída em moinho de facas. Para obtenção dos extratos etanólicos (etanol $80 \%$ - v/v) foi utilizado o método de turboextração (liquidificador industrial), na proporção 1:10 de solvente, durante 30 minutos, com intervalos de 5 minutos com a finalidade de evitar o aquecimento da amostra em temperatura superior a $40^{\circ} \mathrm{C}$. Os materiais obtidos das duas partes da planta foram submetidos a um processo de filtração sob pressão reduzida (Simões et al., 2007; Pacheco et al., 2011). Os filtrados foram concentrados em evaporador rotativo com a temperatura do banho-maria mantida em $38 \pm 1^{\circ} \mathrm{C}$, em seguida foram refrigerados a uma temperatura de $-30^{\circ} \mathrm{C}$ por 12 horas e submetidos a liofilização a $-50{ }^{\circ} \mathrm{C}$ por 72 horas (Simões et al., 2007; Natalli et al., 2011). 


\subsection{Triagem fitoquímica}

A triagem fitoquímica dos extratos para as classes químicas saponinas, ácidos orgânicos, açúcares redutores, polissacarídeos, fenóis e taninos, flavonóides, alcalóides, glicosídeos cardíacos, esteróides, triterpenóides e carotenóides foram realizadas conforme a literatura (Barbosa, 2004).

\subsection{Determinação do potencial antimicrobiano}

Para determinação do potencial antimicrobiano dos extratos obtidos, foram realizados testes de microdiluição em caldo Müller Hinton conforme metodologia padrão para bactérias (NCCLS, 2003). Foram utilizadas para os testes quatro cepas de bactérias: E. coli (ATCC 8739); $S$. aureus (ATCC 25923); B. cereus (ATCC 11778); S. aureus (isolada do Hospital Estadual Dr. Roberto Arnizaut Silvares, São Mateus, ES), que foram mantidas em caldo Müeller-Hinton por 24 horas em temperatura de $35 \pm 2$ ${ }^{\circ} \mathrm{C}$ antes do início dos testes. $\mathrm{O}$ inóculo foi diluído em solução salina a fim de se obter uma suspensão contendo 1,0.108 a 5.108 UFC.mL ${ }^{-1}$, comparando, pela turbidez, com tubo de 0,5 na escala de McFarland.

Para a realização dos testes antimicrobianos, os extratos vegetais foram preparados em diluições com solução de $\mathrm{NaCl}$ 0,9\%, obtendo-se uma concentração de 2000 $\mu \mathrm{g} . \mathrm{mL}^{-1}$ de ambos os extratos. Uma microplaca de 96 poços foi utilizada, dividindo-se os poços em 12 colunas (1 à 12) e 8 linhas (A à H) para cada espécie bacteriana utilizada. Em cada poço foram adicionados $100 \mu \mathrm{L}$ de caldo Müeller-Hinton estéril. De acordo com a Tabela 1, as linhas de "A" a " $E$ " até as colunas 1 a 9 foram utilizadas para os testes com os extratos em análise, perfazendo-se assim testes em quintuplicata.

Nos poços da coluna 1 foram adicionados $100 \mu \mathrm{L}$ do extrato vegetal a $2000 \mu \mathrm{g} \cdot \mathrm{mL}^{-1}$, para se obter uma concentração de $1000 \mu \mathrm{g} \cdot \mathrm{mL}^{-1}$ em cada poço. De cada um destes poços foram pipetados $100 \mu \mathrm{L}$ e transferidos para o poço seguinte (coluna 2), resultando em uma diluição na qual a concentração foi reduzida a metade. O mesmo procedimento foi repetido até os poços da coluna 9 , no qual foi obtida a menor concentração do extrato, 3,9 $\mu \mathrm{g} \cdot \mathrm{mL}^{-1}$. Em seguida foram adicionados 10 $\mu \mathrm{L}$ da suspensão bacteriana previamente preparada em cada poço. Cada microplaca foi utilizada para se testar uma única espécie de bactéria frente ao extrato vegetal específico. As microplacas então foram incubadas em estufa bacteriológica por 24 horas em temperatura de $35 \pm 2{ }^{\circ} \mathrm{C}$.

\subsection{Controle de ensaios antibacterianos}

As colunas 10 a 12 da microplaca foram utilizadas para garantir a ausência de interferentes que alteram os resultados dos testes. Nos poços da coluna 10 foram inseridos o meio de cultura e $10 \mu \mathrm{L}$ da suspensão bacteriana, o que constituiu o controle do microrganismo. Os poços da coluna 11 foram utilizados como controle do meio de cultura nos quais foi adicionado apenas o caldo Müeller-Hinton estéril. Nos poços da coluna 12 foram adicionados o meio de cultura e $100 \mu \mathrm{L}$ da solução do extrato vegetal testado a $1000 \mu \mathrm{g} \cdot \mathrm{mL}^{-1}$ para verificar a ocorrência de alguma contaminação através do material vegetal. Os poços das linhas F e G foram utilizados como controle positivo, utilizando os antibióticos ceftriaxona (30 $\left.\mu \mathrm{g} \cdot \mathrm{mL}^{-1}\right)$ e vancomicina $\left(30 \mu \mathrm{g} \cdot \mathrm{mL}^{-1}\right)$.

Tabela 1. Distribuição das concentrações dos extratos de Cedrela fissilis Vell. nas placas de microdiluições para avalição da atividade antibacteriana.

\begin{tabular}{|c|c|c|c|c|c|c|c|c|c|c|c|c|}
\hline & & & & & & Colun & & & & & & \\
\hline & 1 & 2 & 3 & 4 & 5 & 6 & 7 & 8 & 9 & 10 & 11 & 12 \\
\hline & 1000 & 500 & 250 & 125 & 62,5 & 31,2 & 15,6 & 7,8 & 3,9 & CB & $\mathrm{CM}$ & CE \\
\hline & & & & & Ig. $\mathrm{mL}^{-1}$ & & & & & & & \\
\hline A & EMB & EMB & EMB & EMB & EMB & EMB & EMB & EMB & EMB & $\mathrm{MB}$ & $\mathrm{M}$ & $\mathrm{ME}$ \\
\hline B & EMB & EMB & EMB & EMB & EMB & EMB & EMB & EMB & EMB & MB & $\mathrm{M}$ & $\mathrm{ME}$ \\
\hline C & EMB & EMB & EMB & EMB & EMB & EMB & EMB & EMB & EMB & MB & M & ME \\
\hline D & EMB & EMB & EMB & EMB & EMB & EMB & EMB & EMB & EMB & MB & $\mathrm{M}$ & $\mathrm{ME}$ \\
\hline E & EMB & EMB & EMB & EMB & EMB & EMB & EMB & EMB & EMB & MB & $\mathrm{M}$ & ME \\
\hline $\mathbf{F}$ & CPC & CPC & CPC & CPC & $\mathrm{CPC}$ & & & & & & & \\
\hline G & CPV & CPV & CPV & CPV & CPV & & & & & & & \\
\hline
\end{tabular}

$\mathrm{EMB}=$ Extrato + Meio LB + Bactéria $\mathrm{CB}=$ Controle da Bactéria; MB = Meio + Bactéria; CM = Controle do Meio; $\mathrm{M}$ $=$ Meio; $\mathrm{CE}=$ Controle do Extrato; $\mathrm{ME}=$ Meio + Extrato $\left(1.000 \mu \mathrm{g} \cdot \mathrm{mL}^{-1}\right) ; \mathrm{CPC}=$ Controle Positivo Ceftriaxona $(30$ $\left.\mu \mathrm{g} \cdot \mathrm{mL}^{-1}\right)$ e CPV $=$ Controle Positivo Vancomicina $\left(30 \mu \mathrm{g} \cdot \mathrm{mL}^{-1}\right)$. 


\subsection{Determinação da concentração bactericida mínima (CBM)}

Após o teste de microdiluição, foram coletados 10 $\mu \mathrm{L}$ dos todos os poços que apresentaram inibição bacteriana e, transferidos para placa de Petri contendo agar Müeller-Hinton, seguindo-se de incubação por 24 horas em estufa bacteriológica, em temperatura de $35 \pm$ $2{ }^{\circ} \mathrm{C}$. De acordo com o desenvolvimento bacteriano foi estabelecida a CBM. Os procedimentos realizados para os testes microbiológicos foram todos executados em cabine de proteção biológica, previamente esterilizada por luz ultravioleta por 15 minutos.

\section{Resultados e discussão}

Os rendimentos das extrações etanólicos de de Cedrela fissilis Vell. foram de 1,95\% para cascas e 2,72\% para folhas. Com relação às análises fitoquímica dos extratos foram encontrados diferentes resultados quando comparadas as duas partes do vegetal. Na análise fitoquímica do extrato da casca as substâncias encontradas foram: saponinas, fenóis, taninos pirogálicos e triterpenóides. Para o extrato das folhas detectou-se a presença de taninos catéquicos.

O teste microbiológico realizado com o extrato etanólico da casca de Cedrela fissilis Vell., mostrou atividade antibacteriana frente as cepas de E. coli (ATCC 8739), S. aureus (ATCC 25923), B. cereus (ATCC 11778) e S. aureus (isolada do Hospital Estadual Dr. Roberto Arnizaut Silvares, São Mateus, ES) da coluna 1 até a coluna 4, com concentração inibitória mínima (CIM) de $125 \mu \mathrm{g} \cdot \mathrm{mL}^{-1}$ (Tabela 2). No teste em placa para a determinação da concentração bactericida mínima (CBM) foi possível constatar a propriedade bactericida do extrato etanólico da casca.

O extrato etanólico da folha não apresentou atividade antibacteriana frente a nenhuma das cepas testadas nas concentrações de 3,9 a $1000 \mu \mathrm{g} \mathrm{mL}^{-1}$ (Tabela 3).

Diante da presença de compostos das classes das saponinas, fenóis e taninos pirogálicos e triterpenóides no extrato etanólico das cascas de Cedrela fissilis Vell. é possível explicar a atividade antimicrobiana observada nos testes. De acordo com estudo realizado por Scalbert (1991), o mecanismo de ação antimicrobiana dos taninos é explicado por três hipóteses: (1) taninos inibem enzimas bacterianas e fúngicas e/ou se complexam com os substratos dessas enzimas; (2) a ação dos taninos sobre as membranas celulares dos microrganismos, modificando seu metabolismo, e (3) fundamenta-se na complexação dos taninos com íons metálicos, diminuindo a disponibilidade de íons essenciais para o metabolismo microbiano (Natalli et al., 2011).

O estudo realizado por Schenkel et al. (2001), justifica a atividade antimicrobiana das saponinas, onde relata que o comportamento anfifílico das saponinas e a capacidade de formar complexos com esteroides, proteínas e fosfolipídeos de membranas determinam um número variado de propriedades biológicas para essas substâncias, com destaque a ação sobre membranas celulares. As saponinas podem alterar a permeabilidade das membranas ou até mesmo levar a sua destruição (Castejon, 2011).

Os estudos supracitados fortalecem a hipótese de que os compostos encontrados na análise fitoquímica do extrato etanólico de Cedrela fissilis Vell., sejam os responsáveis pelo potencial antimicrobiano em relação as cepas de E. coli (ATCC 8739), S. aureus (ATCC 25923), B. cereus (ATCC 11778) e S. aureus (Hospitalar).

Tabela 2. Atividade antibacteriana do extrato etanólico das cascas de Cedrela fissilis Vell. frente as bactérias E. coli (ATCC 8739), S. aureus (ATCC 25923), B. cereus (ATCC 11778) e S. aureus (Hospitalar), determinada pelo método de microdiluição, nas concentrações de 1000 à $3,9 \mu \mathrm{g} \cdot \mathrm{mL}^{-1}$.

\begin{tabular}{ccccccccc}
\hline \multirow{2}{*}{$\begin{array}{c}\text { Substância } \\
\left(\mu \mathrm{g} . \mathrm{mL}^{-1}\right)\end{array}$} & \multicolumn{2}{c}{$\begin{array}{c}\text { E. coli } \\
\text { ATCC }\end{array}$} & \multicolumn{2}{c}{$\begin{array}{c}\text { S. aureus } \\
\text { ATCC }\end{array}$} & \multicolumn{2}{c}{$\begin{array}{c}\text { B. cereus } \\
\text { ATCC }\end{array}$} & \multicolumn{2}{c}{$\begin{array}{c}\text { S. aureus } \\
\text { Hospitalar }\end{array}$} \\
\cline { 2 - 9 } & CIM & CBM & CIM & CBM & CIM & CBM & CIM & CBM \\
\hline Controle $^{1}$ & - & - & - & - & - & - & - & - \\
Controle $^{2}$ & + & + & + & + & + & + & + & + \\
Controle $^{3}$ & - & - & - & - & - & - & - & - \\
Extrato $^{4}$ & 125 & 125 & 125 & 125 & 125 & 125 & 125 & 125 \\
Ceftriaxona $^{5}$ & 3,9 & 7,81 & 7,81 & 15,62 & 250 & 500 & 7,81 & 15,62 \\
Vancomicina $^{5}$ & 7,81 & 15,62 & 3,9 & 7,81 & 3,9 & 7,81 & 3,9 & 7,81 \\
\hline
\end{tabular}

1Controle extrato/droga; 2Controle do microrganismo; 3Controle caldo Müeller-Hinton; 4Extrato etanólico nas concentrações 1000,0 a 3,9 $\mu \mathrm{g} . \mathrm{mL}-1$; 5Controle antibacteriano (Ceftriaxona a $30 \mu \mathrm{g} . \mathrm{mL}-1$ e Vancomicina a 30 ug.mL-1); (-) Ausência de crescimento microbiano; (+) Crescimento microbiano; ATCC: America Type Culture Collection. 
Tabela 3. Atividade antibacteriana do extrato etanólico das folhas de Cedrela fissilis Vell. contra bactérias E. coli (ATCC 8739), S. aureus (ATCC 25923), B. cereus (ATCC 11778) e S. aureus (Hospitalar), determinada pelo método de microdiluição, nas concentrações de 1000 a 3,9 $\mu \mathrm{g} \cdot \mathrm{mL}^{-1}$.

\begin{tabular}{|c|c|c|c|c|c|c|c|c|}
\hline \multirow{2}{*}{$\begin{array}{l}\text { Substância } \\
\left(\mu \mathrm{g} \cdot \mathrm{mL}^{-1}\right)\end{array}$} & \multicolumn{2}{|c|}{$\begin{array}{l}\text { E. coli } \\
\text { ATCC }\end{array}$} & \multicolumn{2}{|c|}{$\begin{array}{l}\text { S. aureus } \\
\text { ATCC }\end{array}$} & \multicolumn{2}{|c|}{$\begin{array}{l}\text { B. cereus } \\
\text { ATCC }\end{array}$} & \multicolumn{2}{|c|}{$\begin{array}{l}\text { S. aureus } \\
\text { Hospitalar }\end{array}$} \\
\hline & CIM & CBM & CIM & CBM & CIM & CBM & CIM & CBM \\
\hline Controle $^{1}$ & - & - & - & - & - & - & - & - \\
\hline Controle $^{2}$ & + & + & + & + & + & + & + & + \\
\hline Controle $^{3}$ & - & - & - & - & - & - & - & - \\
\hline Extrato $^{4}$ & + & + & + & + & + & + & + & + \\
\hline Ceftriaxona $^{5}$ & 3,9 & 7,81 & 7,81 & 15,62 & 250 & 500 & 7,81 & 15,62 \\
\hline Vancomicina $^{5}$ & 7,81 & 15,62 & 3,9 & 7,81 & 3,9 & 7,81 & 3,9 & 7,81 \\
\hline
\end{tabular}

${ }^{1}$ Controle extrato/droga; ${ }^{2}$ Controle do microrganismo; ${ }^{3}$ Controle caldo Müeller-Hinton; ${ }^{4}$ Extrato etanólico nas concentrações 1000,0 a 3,9 $\mu \mathrm{g} \cdot \mathrm{mL}^{-1} ;{ }^{5}$ Controle antibacteriano (Ceftriaxona a $30 \mu \mathrm{g} \cdot \mathrm{mL}^{-1} \mathrm{e} \mathrm{Vancomicina} \mathrm{a} 30$ $\left.\mu \mathrm{g} \cdot \mathrm{mL}^{-1}\right) ;(-)$ Ausência de crescimento microbiano; (+) Crescimento microbiano; ATCC: America Type Culture

Collection.

A ausência de atividade antimicrobiana apresentada pelo extrato etanólico das folhas, pode ser explicada pelo fato de ter sido identificado apenas taninos catéquicos, que possivelmente não apresentam atividade nas concentrações testadas. Também é importante destacar um possível sinergismo entre as substâncias encontradas no extrato etanólico, que possam conferir uma atividade antimicrobiana mais efetiva.

\section{Conclusão}

O extrato etanólico das cascas de Cedrela fissilis Vell. contém vários constituintes biologicamente ativos, com potencial antimicrobiano significativo contra as cepas de E. coli (ATCC 8739), S. aureus (ATCC 25923), B. cereus (ATCC 11778) e S. aureus (isolada do hospital Roberto Arnizaut Silvares, São Mateus, ES), mostrando-se um agente bactericida com perspectivas para a obtenção de antibióticos de origem natural, necessitando estudos mais detalhados. Já o extrato etanólico das folhas do vegetal, mostrou-se ineficaz no combate aos agentes bacterianos testados, o que fortalece a prática popular do uso das cascas do cedro (Cedrela fissilis Vell.) com fins medicinais.

\section{Agradecimentos}

Os autores agradecem o apoio financeiro recebido do BNB, FAPES, CNPq, CAPES e UFES.

\section{Referências}

AVORN, J.; SOLOMON, D.H. Cultural and economic that (mis) shape antibiotic use: the nonpharmacologic basis of therapeutics. Annals of Internal Medicine. Philadelphia-US, v.133, p.128$135,2000$.

BARBOSA, W. L. R. Manual para Análise Fitoquímica e Cromatográfica de Extratos Vegetais Revista Científica da UFPA, v. 4, p. 1-19, 2004.

BONELLA A. F.; NATALLI V. D.; CAMIZÃO L. M.; VIEIRA F. A.; BELINELO V. J. Enciclopédia Biosfera, v. 7, n. 13, p. 1-7, 2011.

BRASIL. Politica Nacional de Plantas Medicinais e Fitoterápicos (2006) - http://bvsms.saude.gov.br/ bvs/publicacoes/politica_nacional_fitoterapicos. pdf. Acesso em: 10 de dezembro de 2011.

CARVALHO, P.E.R. Espécies florestais brasileiras: recomendações silviculturais, potencialidades e uso da madeira. Brasília: EMBRAPA, 640p, 1994

CASTEJON F. V. Taninos e Saponinas. Goiânia-GO. 28p. Revisão de Literatura - Programa de PósGraduação em Medicina Veterinária, Universidade Federal de Goiás, 2011.

CHAVES T. P.; DANTAS I. C.; FELISMINO D. C.; VIEIRA K. V. M.; CLEMENTINO E. L. C.; COSTA L. S. (2011) Revista de Biologia e Farmácia, v. 5, n. 2, p.12.

CORRÊA, M. P. Dicionário das plantas úteis do Brasil. Rio de Janeiro: Ministério da Agricultura, IBDF, v. 1, p. 63, 1931.

CORVELLO, W. B. V.; VILLELA F. A.; NEDEL J. L.; PESKE S. T. Revista Brasileira de Sementes, v. 21, n. 
2, p. 23-27, 1999.

COUTINHO, H. D. M.; COSTA, J. G. M.; SIQUEIRAJÚNIOR J. P.; LIMA E. O. In vitro antistaphylococcal activity of Hyptis martiusii Benth against methicillin-resistant Staphylococcus aureusMRSA strains. Revista Brasileira de Farmacognosia, v. 18 (Supl.), p. 670-675, 2008.

DEL FIOL, F.S.; LOPES, L.C.; TOLEDO, M.I.; BARBERATO-FILHO, S. Perfil de prescrições e uso de antibióticos em infecções comunitárias. Rev. Soc. Bras. Med. Trop. Vol.43, n.1, p.68-72, 2010.

FREITAS, A. G.; FARIAS, E.T.; LIMA, M.C.A.; SOUSA, I.A.; XIMENES, E.A. Atividade antiestafilocócica do Plantago major L. In: Revista Brasileira de Farmacognosia. v. 12, supl., p. 64-65, 2002.

LEITÃO, S. G.; CASTRO, O.; FONSECA, E. M.; JULIÃO, L. S.; TAVARES, E. S.; LEO, R. R. T.; VIEIRA, R.C.; OLIVEIRA, D. R.; LEITÃO, G. G.; MARTINO, V.; SULSEN, V.; BARBOSA, Y. A. G.; PINHEIRO, D. P. G.; SILVA, P. E. A.; TEIXEIRA, D. F.; LOURENÇO, M. C. S. Screening of Central and South American plant extracts for antimycobacterial activity by the Alamar Blue test. Revista Brasileira de Farmacognosia, v. 16, n. 1, p. 6-11, 2006.

LORENZI, H. Árvores brasileiras: manual de identificação e cultivo de plantas arbóreas nativas do Brasil. Nova Odessa: Plantarium, p. 241, 1992.

LORENZI, H. e MATOS, F.J.A. Plantas Medicinais no Brasil: nativas e exóticas. Nova Odessa, São Paulo: Instituto Plantarum, 2002. 512p.

LORENZI, H.; MATOS, F. J. A. Plantas medicinais no Brasil: nativas e exóticas. 2. ed. Nova Odessa: Editora Plantarum, p. 371, 2008.

NATALLI, V. D.; BARCELOS, R. M.; PINTO, A. P. A.; RESENDE, K. M.; BELINELO, V. J. Investigação fitoquímica e atividade antimicrobiana de Amaranthus viridis L. (Amaranthaceae). Enciclopédia Biosfera, v. 7, n. 12, p. 1-8, 2011.

NCCLS. National Committee for Clinical Laboratory Standards. M7-A6. Metodologia dos testes de sensibilidade a agentes antimicrobianos por diluição para bactéria de crescimento aeróbico, $\mathrm{v}$. 23, n. 2, p. 1-48, 2003.

PACHECO, T. F.; CAMPOS, M. S. T.; SANTANA, A. S. O.; BELINELO, V. J., PÁDUA , S. A. P. Avaliação in vitro da atividade antifúngica de extrato aquoso de Emilia sonchiforlia (L.) DC. (Asteraceae). Enciclopedia Biosfera, v. 7, n. 12, p. 1-10, 2011.

REITZ, R.; KLEIN, R. M. \& REIS, A. Projeto madeira do Rio Grande do Sul. Itajaí: IOESC, 525p, 1983.

RIZZINI, C. T. Árvores e madeiras úteis do Brasil: manual de dendrologia brasileira. São Paulo: Edgard Blücher, 296p, 1981.

SALVAGNINI, L. E.; OLIVEIRA, J. R. S.; SANTOS, L. E.; MOREIRA, R. R. D.; PIETRO, R. C. L. R. Avaliação da atividade antibacteriana de folhas de Myrtus communis L. (Myrtaceae). Revista Brasileira de Farmacognosia, v. 18, n. 2, p. 241-244, 2008.

SCALBERT, A. Antimicrobial properties of tannins. Phytochemistry, v. 30, n. 12, p. 3875-3883, 1991.

SCHENKEL,E.P.; GOSMANN,G.; ATHAYDE,M.L.SAPONINAS. IN: SIMÕES, C.M.; SCHENKEL, E. P.;GOSMANN, G.; MELLO, J. C.P.; MENTZ, L.A.; PETROVICK, P. R. Farmacognosia: da planta ao medicamento. 3. ed. Porto Alegre: Ed. UFGRS/Ed. UFSC, cap.27, p. 597-619, 2001.

SILVA, J. G.; SOUZA, I. A.; HIGINO, J. S.; SIQUEIRAJUNIOR, J. P.; PEREIRA, J. V.; PEREIRA, M. S. V. Atividade antimicrobiana do extrato de Anacardium occidentale Linn. Em amostras multiresistentes de Staphylococcus aureus. Revista Brasileira de Farmacognosia, v. 17, n. 4, p. 572-577, 2007.

SILVA, M. A. R.; HIGINO, J. S.; PEREIRA, J. V.; SIQUEIRA-JÚNIOR, J. P.; PEREIRA, M. S. V. Antibiotic activity of the extract of Punica granatum Linn. over bovine strains of Staphylococcus aureus. Revista Brasileira de Farmacognosia, v. 18, n. 2, p. 209-212, 2008.

SIMÕES, C. M. O.; SCHENKEL, E. P.; GOSMANN, G.; MELLO, J. C. P.; MENTZ, L. A.; PETROVICK, P. R. Farmacognosia: da planta ao medicamento. 6. ed. Florianópolis: UFSC. 1104p, 2007.

WANNMACHER, L. Uso indiscriminado de antibióticos e resistência microbiana: Uma guerra perdida? Brasília: Organização Pan-Americana da Saúde; v.1, n.4, 2004.

WHITE, R. J.; MARGOLIS, P. S.; TRIAS, J.; YUAN, Z. Targeting metalloenzymes: a strategy that works. Current Opinion in Pharmacology, v. 3, n. 5, p. 502507, 2003. 